\title{
Assessment of the Burden on Caregivers of Patients with Mental Disorders- A cross-sectional study
}

\section{*Pratiksha Acharya ${ }^{1}$, Hari Prasad Upadhyay ${ }^{2}$, N.Loganathan ${ }^{1}$}

${ }^{1}$ Department of Nursing

${ }^{2}$ Department of Community Medicine, College of Medical Sciences-Teaching Hospital, Bharatpur, Chitwan, Nepal.

\section{*Corresponding Author:}

\section{Ms. Pratiksha Acharya}

Contact: nisha.ach50089@gmail.com,+977-9843769992

\begin{abstract}
Introduction: Caregivers play an important role in the management of all chronic mental illnesses. Thus the aim of this study was to assess the burden and to find out the association between the level of burden among caregivers of mentally ill patients and related variables.

Material and Method: An analytical cross-sectional, study was conducted among the caregivers of mentally ill patients visiting at selected Hospital of Bharatpur. Burden Assessment Schedule (BAS) tool was used to collect the data. A chi-square test was used to find the association between levels of burden with related variables. A P-value of less than 0.05 was considered as statistically significant.

Results: Research showed that among 204 caregivers $61.8 \%$ had a moderate level of burden and none of the caregivers had a mild level of burden however $38.2 \%$ had a severe level of burden. The statistically significant factors that affect the level of burden in the caregivers are the place of residence, relation with the patient, duration of mental illness, duration of caregiving and monthly expenditure for treatment are the statistically significant variables to the level of burden.

Conclusion: More than one-third of the caregivers have a severe level of burden. The level of burden is high among the female as among the male. Caregivers who are married and education status less than the primary level have a high level of burden.
\end{abstract}

Keywords: burden, caregivers, cross-sectional, mentally ill patients

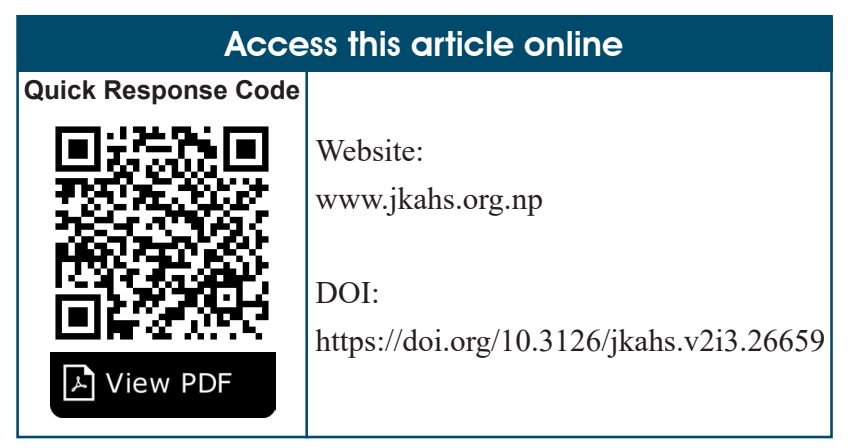

\section{INTRODUCTION}

The World Health Organization defines "Health" as a state of complete physical, mental, social, and spiritual wellbeing, and not merely the absence of any disease or infirmity. ${ }^{1}$ WHO defines, Mental health as the state

\section{Article Info.}

\section{How to cite this article?}

Acharya P, Upadhyay HP, Loganathan N. Assessment of the Burden on Caregivers of Patients with Mental Disorders- A cross-sectional study. Journal of Karnali Academy of Health Sciences. 2019;2(3): 220-226.

Received: 15 Oct., Accepted: 28 Nov., Published: 11 Dec. 2019

Conflict of Interest: None, Source of Support: Self

of well-being in which an individual realizes his or her own abilities, can cope with the normal stresses of life, can work productively and is able to make a contribution to his or her community. ${ }^{2}$ Mental health is an integral and essential component of health. 
Mental health includes our emotional, psychological, and social well-being. A caregivers has been defined as a person who has been living with the patient and has been closely involved in his/her activities of daily living, health care and social interaction. ${ }^{3}$ The problem is particularly troublesome in developing countries. ${ }^{3}$ Caregivers plays an important role in the management of all the chronic mental illness. They may be family, friends or relatives of the patient. ${ }^{3}$ Caregivers are all persons who support and help a person in need of care regularly because of personal not professional reasons. That means every kind of help and support. It doesn't need to be health cares in the narrow sense. ${ }^{4}$ Psychiatric disorders are as old as human life. The prevalence of psychiatric disorders and their undesired personal, familial and social effects have increased simultaneously with population growth and urbanity. Mental health is the invisible problem in international development. Globally, mental health problems are serious public health concern. Around 450million people currently suffer from mental condition, placing mental disorder among the leading cause of ill health and disability worldwide.1 Walker, McGee and Druss (2015) have estimated that $14.3 \%$ of deaths globally every year are attributable to mental disorders and it is ranked among the most considerable causes of death. ${ }^{6}$ National Alliance on mental illness (2016) estimated that one in 5 adults experiences a mental health condition every year. ${ }^{15}$ One in 17 lives with a serious mental illness such as schizophrenia or bipolar disorder. In addition to a person's directly experiencing a mental illness, family, friends and communities are also affected. Half of mental health conditions begin by age of 14 , and $75 \%$ of mental health conditions develop by age of 24 . The normal personality and behavior changes of adolescence may mimic or mask symptoms of a mental health condition. Early engagement and support are crucial to improving outcomes and increasing the promise of recovery. ${ }^{5}$ In the context of Nepal very few research were conducted in this issue, so the finding of this research will be milestone for those researcher who want to do research in this area. Thus the aim of this study was to assess the burden and to find out association between level of burden among caregivers of mentally ill patients and related variables.

\section{MATERIALS AND METHODS}

Analytical cross-sectional study was conducted among caregivers of mentally ill patients visiting at Chitwan Medical College-Teaching Hospital, Bharatpur-10. A study conducted by Shyangwa showed that, the level of burden among mentally ill patients is $14 \%,{ }^{7}$ taking this as a prevalence, sample size was calculate by using the following formula;

By adding $10 \%$ non-response rate the optimum sample size of this research was 204. Information from the caregivers was collected by using non probability sampling technique. Burden Assessment Scheduled (BAS) was used to collect the information which was developed by Schizophrenia Research Foundation (SCARF), India, to assess the burden on family caregivers of people with chronic mental illness. This is a semi-quantitative questionnaire consisting of 40item scale measuring 9 different areas of objective and subjective caregiver burden. Each item is rated on a 3-point scale. The responses are 'not at all', 'to some extent', and 'very much'. Some of the items are reverse coded. Scores range from 40 to 120 with higher scores indicating greater burden. If the score is 0-40 indicate mild level of burden, 41-80 indicate the moderate level of burden and 81-120 indicate the severe level of burden. 8 The pre test was conducted (in College of Medical Sciences, among the $10 \%$ of the caregivers) and reliability of the tool was checked by using Cronbach's alpha in SPSS and its value was 0.7 which showed the acceptable level. Ethical approval was taken from Institution Review Committee Board of College of Medical Science and Teaching Hospital. Collected data using tool was as checked, reviewed, organized for accuracy and completeness and coded before entry. Data were entered into the Epidata (A software designed for data entry) Version 3.1 and statistical package for the social sciences (SPSS-A software designed for data analysis) 20.0. After double checking the completeness of the data, data was analyzed using SPSS using descriptive and inferential statistics. In descriptive statistics result was presented by using frequency, percentage, Mean, Standard deviation and using pie-diagram. In the inferential statistics, Chi-square test was used to 
find association between level of burden with related variables. In this research level of burden among the caregivers is dependent variable whereas Age Gender, Marital status, Educational Status, Occupation, Family Monthly Income, Types of family, place of residence, Relation with the patient, Duration of illness, Duration of care giving, Monthly expenditure for treatment were independent variables.

\section{RESULT}

In this research 204 respondents were surveyed to assess the Burden on Caregivers of Patients with Mental Disorders. Majority of the respondent's age group were 19-29 years and majority of them were female by gender and married by marital status (Table 1).

\section{Table 1: Sociodemographic Characteristics of the respondents $(n=204)$}

\begin{tabular}{ccc}
\hline Demographic & Frequency & Percentage \\
Variables & (f) & $(\%)$ \\
\hline
\end{tabular}

Age (in years)

19-29

30-39

40-49

50-60

22

34.8

23

31.4

10.8

Gender

Female

106

Male

98

52

48

Marital status

Married

166

81.4

Unmarried

38

Educational status

Primary level and

below

Secondary level

Higher secondary

Graduate and above

\section{Occupational status}

Agriculture

Business

\begin{tabular}{lcc}
\hline $\begin{array}{c}\text { Demographic } \\
\text { Variables }\end{array}$ & $\begin{array}{c}\text { Frequency } \\
\text { (f) }\end{array}$ & $\begin{array}{c}\text { Percentage } \\
\text { (\%) }\end{array}$ \\
\hline Government sector & 13 & 6.4 \\
Household work & 48 & 23.5 \\
Private sector & 24 & 11.8 \\
Student & 28 & 13.7
\end{tabular}

Family monthly

Income

$<10000$ Rs. 9.3

10000-20000 Rs. 30.9

20001-30000 Rs. 18.6

$>30000$ Rs.

Type of family

Joint 82

40.2

Nuclear

59.8

Place of residence

Rural 96

47.1

Urban

108

Relation with the patient

Child

16.2

Parent

30.9

Siblings

Spouse

35.8

\section{Duration of mental}

\section{illness}

3-6 Month

6- 12 Month

$>1$ year

\section{Duration of care}

giving

3-6 Month

13.2

6- 12 Month

$>1$ year

59.8

\section{Monthly Expenditure}

for treatments

$<3000$ Rs.

36.8

3000-6000 Rs.

39.2

6001-9000 Rs.

8.8

$>9000$ Rs.

15.2 


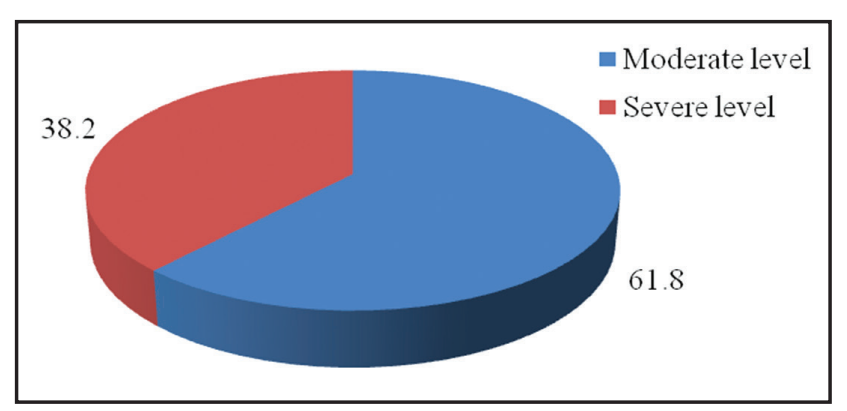

Finding of this research showed that $61.8 \%$ of the caregivers had moderate level of burden, none of the caregivershad mild level of burden and $38.2 \%$ had severe level of burden (Figure 1).

Figure 1: Level of burden among the caregivers of mentally ill patients $n=204$

Table 2: Mean, SD of burden among the Caregivers of mentally ill patients based upon nine factorial configurations $(n=204)$

\begin{tabular}{clccc}
\hline \hline S.N. & \multicolumn{1}{c}{ Factorial Configuration } & Maximum Score & Mean $(\mathbf{X})$ & SD \\
\hline 1 & Spouse related & 15 & 4.25 & 3.89 \\
2 & Physical and mental health & 18 & 12.46 & 1.88 \\
3 & External support & 15 & 9.3 & 1.33 \\
4 & Caregivers routine & 15 & 10.53 & 1.52 \\
5 & Support of patient & 9 & 6.54 & 0.91 \\
6 & Taking responsibility & 15 & 10.97 & 1.66 \\
7 & Other relation & 9 & 5.07 & 1.46 \\
8 & Patient's behavior & 12 & 8.59 & 1.85 \\
9 & Caregiver's strategy & 12 & 7.76 & 1.12 \\
\hline Overall Burden among caregivers & $\mathbf{1 2 0}$ & $\mathbf{7 5 . 7 5}$ & $\mathbf{1 0 . 6}$ \\
\hline
\end{tabular}

Research showed that in spouse related category the mean $\pm \mathrm{SD}$ of score was $4.25 \pm 3.89$. In physical and mental health related category the mean \pm SD of score was $12.46 \pm 1.88$. Also for the category external support the mean $\pm \mathrm{SD}$ of the score was $9.30 \pm 1.33$. While in caregiver's routine related category the mean $\pm \mathrm{SD}$ of the score was. The mean $\pm \mathrm{SD}$ of score in support of patients related category was $6.54 \pm 0.91$. For the category taking responsibility the mean $\pm \mathrm{SD}$ of the score was $10.97 \pm 1$.66. Likewise, relation related category the mean $\pm \mathrm{SD}$ $5.07 \pm 1.46$. For the category patient's behavior mean $\pm \mathrm{SD}$ of the score was $8.59 \pm 1.85$ and for the caregiver's strategy the mean \pm SD $7.76 \pm 1.12$. The overall burden among the caregivers of mentally ill patients the mean mean \pm SD was $75.75 \pm 10.57$ (Table 2).

Table 3: Association between level of burden as with their selected variables. $(n=204)$

\begin{tabular}{|c|c|c|c|c|c|c|}
\hline \multirow{2}{*}{$\begin{array}{c}\text { Demographic } \\
\text { variables }\end{array}$} & \multicolumn{2}{|c|}{ Moderate level } & \multicolumn{2}{|c|}{ Severe level } & \multirow{2}{*}{$\chi 2$ value } & \multirow{2}{*}{ p-value } \\
\hline & Frequency & Percentage & Frequency & Percentage & & \\
\hline \multicolumn{7}{|l|}{ Age (in years) } \\
\hline $19-29$ & 48 & 38.10 & 23 & 29.50 & \multirow{4}{*}{7.3} & \multirow{4}{*}{0.63} \\
\hline 30-39 & 31 & 24.60 & 16 & 20.50 & & \\
\hline $40-49$ & 31 & 24.60 & 33 & 42.30 & & \\
\hline $50-60$ & 16 & 12.70 & 6 & 7.70 & & \\
\hline \multicolumn{7}{|l|}{ Gender } \\
\hline Female & 58 & 46.00 & 48 & 61.50 & \multirow{2}{*}{4.61} & \multirow{2}{*}{0.31} \\
\hline Male & 68 & 54.00 & 30 & 38.50 & & \\
\hline
\end{tabular}




\begin{tabular}{|c|c|c|c|c|c|c|}
\hline \multirow{2}{*}{$\begin{array}{c}\text { Demographic } \\
\text { variables } \\
\end{array}$} & \multicolumn{2}{|c|}{ Moderate level } & \multicolumn{2}{|c|}{ Severe level } & \multirow{2}{*}{$\chi^{2}$ value } & \multirow{2}{*}{ p-value } \\
\hline & Frequency & Percentage & Frequency & Percentage & & \\
\hline \multicolumn{7}{|l|}{ Marital status } \\
\hline Married & 99 & 78.60 & 67 & 85.90 & \multirow{2}{*}{1.7} & \multirow{2}{*}{0.19} \\
\hline Unmarried & 27 & 21.40 & 11 & 14.10 & & \\
\hline \multicolumn{7}{|l|}{ Educational status } \\
\hline Primary level \& below & 43 & 34.10 & 36 & 46.20 & \multirow{4}{*}{3.65} & \multirow{4}{*}{0.31} \\
\hline Secondary level & 53 & 42.10 & 26 & 33.30 & & \\
\hline Higher secondary & 13 & 10.30 & 9 & 11.50 & & \\
\hline Graduate and above & 17 & 13.50 & 7 & 9.00 & & \\
\hline \multicolumn{7}{|l|}{ Occupational status } \\
\hline Agriculture & 31 & 24.60 & 16 & 20.50 & \multirow{7}{*}{10.52} & \multirow{7}{*}{0.11} \\
\hline Business & 23 & 18.30 & 11 & 14.10 & & \\
\hline Daily wages & 3 & 2.40 & 7 & 9.00 & & \\
\hline Government sector & 7 & 5.60 & 6 & 7.70 & & \\
\hline Household work & 25 & 19.80 & 23 & 29.50 & & \\
\hline Private sector & 19 & 15.10 & 5 & 6.40 & & \\
\hline Student & 18 & 14.30 & 10 & 12.80 & & \\
\hline \multicolumn{7}{|l|}{ Family Monthly Income } \\
\hline$<10000$ & 9 & 7.10 & 10 & 12.80 & \multirow{4}{*}{6.42} & \multirow{4}{*}{0.93} \\
\hline $10000-20000$ & 46 & 36.50 & 17 & 21.80 & & \\
\hline 20001-30000 & 20 & 15.90 & 18 & 23.10 & & \\
\hline$>30000$ & 51 & 40.50 & 33 & 42.30 & & \\
\hline \multicolumn{7}{|l|}{ Type of family } \\
\hline Joint & 58 & 46.00 & 24 & 30.80 & \multirow{2}{*}{4.66} & \multirow{2}{*}{0.31} \\
\hline Nuclear & 68 & 54.00 & 54 & 69.20 & & \\
\hline \multicolumn{7}{|l|}{ Place of residence } \\
\hline Rural & 52 & 41.30 & 44 & 56.40 & \multirow{2}{*}{4.43} & \multirow{2}{*}{$0.04 *$} \\
\hline Urban & 74 & 58.70 & 34 & 43.60 & & \\
\hline \multicolumn{7}{|c|}{ Relation with the patient } \\
\hline Child & 29 & 23.00 & 4 & 5.10 & \multirow{4}{*}{63.06} & \\
\hline Parent & 48 & 38.10 & 15 & 19.20 & & $<0001 *$ \\
\hline Siblings & 30 & 23.80 & 5 & 6.40 & & $<0.001$ \\
\hline Spouse & 19 & 15.10 & 54 & 69.20 & & \\
\hline Duration of mental illt & & & & & & \\
\hline 3-6 Month & 26 & 20.60 & 0 & & & \\
\hline 6- 12 Month & 52 & 41.30 & 4 & 5.10 & 64.98 & $<0.001 *$ \\
\hline$>1$ year & 48 & $38.10 \%$ & 74 & 94.90 & & \\
\hline Duration of caregiving & & & & & & \\
\hline 3-6 Month & 27 & 21.40 & 0 & 0.00 & & \\
\hline 6- 12 Month & 51 & 40.50 & 4 & 5.10 & 65.01 & $<0.001 *$ \\
\hline$>1$ year & 48 & 38.11 & 74 & 94.90 & & \\
\hline
\end{tabular}




\begin{tabular}{|c|c|c|c|c|c|c|}
\hline \multirow{2}{*}{$\begin{array}{c}\text { Demographic } \\
\text { variables }\end{array}$} & \multicolumn{2}{|c|}{ Moderate level } & \multicolumn{2}{|c|}{ Severe level } & \multirow{2}{*}{$\chi^{2}$ value } & \multirow{2}{*}{ p-value } \\
\hline & Frequency & Percentage & Frequency & Percentage & & \\
\hline \multicolumn{7}{|c|}{ Monthly Expenditure for treatment } \\
\hline$<3000$ & 56 & 44.40 & 19 & 24.40 & \multirow{4}{*}{8.81} & \multirow{4}{*}{$0.04 *$} \\
\hline $3001-6000$ & 43 & 34.10 & 37 & 47.40 & & \\
\hline $6001-9000$ & 11 & 8.70 & 7 & 9.00 & & \\
\hline$>9000$ & 16 & 12.70 & 15 & 19.20 & & \\
\hline
\end{tabular}

Statisistically significant variables with level of burden and other related variables were: place of residence, relation with the patients, and duration of mental illness, duration of care giving and monthly expenditure for treatment (Table 3).

\section{DISCUSSION}

In this research majority of the caregivers were in the age group 19-29 years and majority of them were female by gender and married by marital status. Finding showed that $61.8 \%$ had moderate level of burden and none of the caregivers had mild level of burden however $38.2 \%$ had severe level of burden. A study conducted by Sujata Chodankar Walke revealed that $59.1 \%$ had moderate burden and $40.9 \%$ severe burden. ${ }^{9}$ Overall burden scores of family caregivers revealed that that nearly 27 (45\%) had mild burden, 8 (13.3\%) had moderate burden and remaining 9 (15\%) had severe burden and 16 (26.7\%) had no burden.10 The results indicate that $49 \%$ of caregivers were having high burden of care while equal number of caregivers $(50 \%)$ were having low and high objective and subjective burden on Burden assessment scale.10 Study of Yusuf AJ and Nuhu FT showed that emotional distress was in $79.84 \%$ of the caregivers (95\% CI 72.82-86.86).11 Caregivers of aged 4554 years reported the highest levels of depressive symptoms, caregivers aged 35-44 reported the strongest sense of abandonment. Caregivers who were the adult children of patients with disease (cancer) and who were employed reported high levels of depressive symptoms. Feeling abandoned (a portion of caregiver burden) was more prevalent in female, non-spouse, and adult children caregivers, and adult children caregivers of patients with early stage cancer and patients with multiple symptoms reported a high perception of disruption in their schedule due to providing care. Caregivers whose patients died early following diagnosis (between waves I and II) reported the highest depressive symptoms, burden, and impact on schedule.12 Association between level of burden among the caregivers of mentally ill patients with their selected demographic variables. Significant value was found between the area of living, relationship with the patient, duration of mental illness, duration of caregiving and monthly expenditure for treatment. This result is supported by Sujata Chodankar Walke (2018), which revealed that significant association between duration of care giving, relation with the patient and duration of mental illness.9 Study showed the association $(p<0.05$ level) between the level of burden with selected socio demographic variables such as age, occupation, monthly income, maritalstatus, type of family, relation with the client, area of living, and monthly expenditure for treatment.10 Results showed the significant association among BAS, GHQ, their subscales and other demographic variables such as socio-economic status, education, marital status, area of living etc. and these variables were significant contributors on burden of care. Factors associated with emotional distress in the caregivers were family size, education, financial support, patient gender and relationship with the patient. ${ }^{11}$ Clinical severity and burden indices were similar for the psychiatric illness groups. However, relatives of patients with psychotic symptoms, unco-operative behavior, marital instability and unemployment had significantly higher burden score, while patients from such families perceived a wider social support network. Financial burden was greater than effect on family routines. ${ }^{13}$ 


\section{CONCLUSION}

More than one third of the caregivers have severe level of burden. The level of burden is high among the female as among the male. Caregivers who are married and education status less than primary level have high level of burden. Also, the caregivers who are from nuclear family and whose patient's duration of mental illness more than one year had severe level of burden. The statistically significant factors that affect to the level of burden are: place of residence, relation with the patients, and duration of mental illness, duration of care giving and monthly expenditure for treatment.

\section{Acknowledgements}

We are thankful to all the caregivers, hospital staff of Chitwan Medical College staff for their valuable support and time during data collection.

\section{Limitations}

This study has enrolled only in one Medical College among medical caregivers, future researcher can conduct this study among various college and among all caregivers.

\section{REFERENCES}

1. K Park, Parks textbook of Preventive and Social Medicine, seventh edition, M/s Banarsidas Bhanot publishers, page no: 12 .

2. World health organization. Mental health: a state of well-being. 2014 Aug.

3. Medicineplus. trusted health information for you. Caregivers related issues. 2018 Feb.

4. Center for global health research and studies. Incidence and prevalence of mental disorder.2015 Jan.

5. Shyangwa PM, Shakya DR, Adhikari BR, Pandey AK, Sapkota N, Deo BK, Niraula SR. Community Based Survey on Psychiatric Morbidity in Eastern Nepal. JNMA; journal of the Nepal Medical Association. 2014 Oct 1;52(196):997-1004.

6. Walke SC, Chandrasekaran V, Mayya SS. Caregiver burden among caregivers of mentally ill individuals and their coping mechanisms. Journal of neurosciences in rural practice. 2018;9(2):180.

7. Shyangwa PM, Shakya DR, Adhikari BR, Pandey AK, Sapkota N, Deo BK, Niraula SR. Community Based Survey on Psychiatric Morbidity in Eastern Nepal. JNMA; journal of the Nepal Medical Association. 2014 Oct 1;52(196):997-1004.

8. Sai laxmi Gandi and Thennarasu K. Burden among Caregivers of Clients with Depression - A Scientific Study. International Journal of Advanced Nursing Science and Practice 2012; 1(1): 20-28.

9. Swaroop N, Shilpa Ravi, B. Ramakrishna Goud, Maria Archana, Tony M Pius, Anjali Pal, Vimal John, Twinkle Agrawal, Geetha Jayaram. Burden among Caregivers of Mentally- Ill Patients: A Rural Community Based Study. International Journal of Research And Development of Health.2013(2):29-34.

10. Anjum W, ahida Anjum HR, Chaudhry HR, Irfan M. Burden of Care In Caregivers Of $P$ Burden of Care In Caregivers of Patients With Schizophrenia And Epilepsy. JPPS. 2010;7(2):79-83.

11. S.S, S.V, H.N. R, A descriptive study to assess the burden among family care givers of mentally ill clients. IOSR Journal of Nursing and Health Science, 2014: 3(3): 61-67

12. Yusuf AJ, Nuhu FT. Factors associated with emotional distress among caregivers of patients with schizophrenia in Katsina, Nigeria. Social psychiatry and psychiatric epidemiology. 2011 Jan 1;46(1):11-6.

13. Given B, Wyatt G, Given C, Gift A, Sherwood P, DeVoss D, Rahbar M. Burden and depression among caregivers of patients with cancer at the end-of-life. InOncology nursing forum 2004 Nov 16 (Vol. 31, No. 6, p. 1105). NIH Public Access.

14. Ohaeri JU. Caregiver burden and psychotic patients' perception of social support in a Nigerian setting. Social psychiatry and psychiatric epidemiology. 2001 Apr 1;36(2):86-93.

15. National Alliance on mental illness (NAMI). Mental health condition. 2016 Feb 